International Journal of Environmental Research and

Public Health

ISSN 1660-4601

www.mdpi.com/journal/ijerph

Article

\title{
The Impact of the 2002 Delaware Smoking Ordinance on Heart Attack and Asthma
}

\author{
John Moraros ${ }^{1}{ }^{*}$, Yelena Bird ${ }^{1}$, Shande Chen ${ }^{2}$, Robert Buckingham ${ }^{1}$, Richard S. Meltzer ${ }^{1}$, \\ Surasri Prapasiri ${ }^{1}$ and Luis H. Solis ${ }^{1}$
}

1 School of Public Health, University of Saskatchewan, 107 Wiggins Road, Saskatoon, Saskatchewan, S7N 5E5, Canada; E-Mails: yelena.bird@usask.ca (Y.B.);

b.buckingham@usask.ca (R.B.); meltzer@zianet.com (R.S.M.); surasri@nmsu.edu (S.P.); luisolis@ hotmail.com (L.H.S.)

2 Department of Biostatistics, University of North Texas Health Science Center at Fort Worth, 3500 Camp Bowie Blvd., Fort Worth, TX 76107, USA; E-Mail: chande.chen@ unthsc.edu

* Author to whom correspondence should be addressed; E-Mail: john.moraros @ usask.ca;

Tel.: +1-306-966-8578; Fax: +1-306-966-7920.

Received: 1 November 2010; in revised form: 23 November 2010 / Accepted: 29 November 2010 / Published: 2 December 2010

\begin{abstract}
In the United States, smoking is the leading cause of death - having a mortality rate of approximately 435,000 people in 2000 - accounting for $8.1 \%$ of all US deaths recorded that year. Consequently, we analyzed the Delaware Hospital Discharge Database, and identified state and non-state residents discharged with AMI or asthma for the years 1999 to 2004. Statistical data analysis compared the incidence of AMI or asthma for each group before (1999-2002) and after (2003-2004) the amendment. As a result, we found that pre-ordinance and post-ordinance quarterly rates of AMI for Delaware residents were $451(\mathrm{se}=21)$ and $430(\mathrm{se}=21)$ respectively, representing a $4.7 \%$ reduction. Over the same time period, there was negligible change in the incidence of AMI for non-Delaware residents. After adjusting for population growth, the Risk Ratio (RR) for asthma in Delaware residents post-ordinance was 0.95 (95\% CI, 0.90 to 0.999), which represented a significant reduction $(\mathrm{P}=0.046)$. By comparison, non-Delaware residents had an increased RR for asthma post-ordinance of 1.62 (95\% CI, 1.46 to 1.86 ; $\mathrm{P}<0.0001)$. The results suggest that Delaware's comprehensive non-smoking ordinance effectively was associated with a statistically significant decrease in the incidence of AMI and asthma in Delaware residents when compared to non-Delaware residents.
\end{abstract}


Keywords: acute myocardial infarction; asthma; smoking; secondhand smoke exposure; prevention; health promotion

\section{Introduction}

In the United States (US), smoking is the leading cause of death - having a mortality rate of approximately 435,000 people in 2000 - accounting for $8.1 \%$ of all US deaths recorded that year [1]. Consequently, the detrimental effects of smoking and exposure to secondhand smoke (SHS) have been well established in medical literature, which demonstrated a strong association with cardiovascular disease and acute myocardial infarction (AMI) [2]. As a result, smoking and SHS have been shown to be dangerous to respiratory health of all people with special consideration given to those afflicted with respiratory disease - especially asthma sufferers [3,4]. Decades of evidence regarding the hazards of smoking and exposure to SHS have led many communities across the western world to institute comprehensive non-smoking ordinances (which include the workplace, restaurants, and bars) and has led others to amend partial ordinances to become comprehensive.

Recently, four different studies have demonstrated significant decreases in the incidence of AMI after the enactment and implementation of a comprehensive local smoke-free ordinance [5-7]. The cities of Pueblo, Colorado, and Helena, Montana in the US have shown between 27-40\% decreases in the incidence of AMI. Further, the Piedmont region of Italy has found an $11 \%$ decrease in AMI in individuals under the age of 60 after the implementation of a strong anti-smoking ban. In addition, a recent study conducted in the metropolitan area of Toronto, Canada, concluded that not only incidences of AMI were reduced, but also asthma, stroke, pneumonia, and chronic obstructive pulmonary disease were also affected [8]. Interestingly, all four studies reported a significant improvement in cardiovascular health benefits in locations which had not initiated comprehensive smoking ordinances previously. In addition, studies that include asthma, such as Rayens et al., have shown a $22 \%$ decrease in asthma emergency department visits post-law [9]. Therefore, these findings confirmed the long-standing assumption that comprehensive smoking ordinances may represent a practical and effective tool in the fight to reduce the health care burden due to cardiovascular diseases.

Currently, eight US states have implemented comprehensive non-smoking ordinances [10]. Notably, $54.8 \%$ of the US population is protected by at least a partial non-smoking ordinance (workplaces and/or restaurants and/or bars), including $21.7 \%$ who are protected by a comprehensive ordinance (covering workplaces, restaurants, and bars) [11]. However, previous studies did not discuss the potential health benefits derived from the legislative change from a partial to a comprehensive ban as well as the consequences of statewide non-smoking ordinances. As a result, the purpose of this study was to examine and determine the effects of a comprehensive non-smoking ban on the hospitalization rates of patients due to AMI and asthma among residents and non-residents of the state of Delaware, in the US. 


\section{Experimental Section}

\subsection{Setting}

According to US census data, the population of Delaware was 783,600 in 2000 and estimated to be 843,524 in 2005 [12-14]. Additionally, over the time period from 1999 to 2004, Delaware had a higher percentage of smokers when compared to the national US average (25.4\% versus $22.8 \%$ in 1999 and $24.4 \%$ versus $20.9 \%$ in 2004) [15,16].

\subsection{Ordinance}

The Delaware Clean Indoor Air Act of 1994 became comprehensive in 2002. It was amended to encompass all enclosed indoor areas accessible to the general public, which included restaurants, bars, and casinos [17]. Prior to the amendment, such hospitality venues were exempt from the smoking ban. At the time, the new ordinance was considered one of the most aggressive non-smoking bans in the country. Accordingly, the Delaware Department of Public Health reported 99.6\% compliance in bars and restaurants, and the Delaware Department of Labor reported $100 \%$ compliance in other workplaces in the first year of the new regulation [18].

\subsection{Delaware Database}

The state of Delaware hospital discharge database is maintained by the Delaware Department of Health and Social Services. Accordingly, all non-federal, acute-care, and short stay Delaware hospitals report their inpatient discharge information to the Department of Health. Those hospitals or hospital systems include A.I duPont, St. Francis, Christiana Care Health System (Wilmington and Christiana Care), Bayhealth Medical System (Kent General and Milford), Beebe and Nanticoke [18]. Furthermore, there is only one federal hospital in Delaware which is not included in the database - the Wilmington VA Medical Center.

\subsection{Data Collection}

The authors contacted the Delaware Department of Health and Social Services and a formal request was made to the Delaware hospital discharge database for the years 1999 to 2004 (the most current data available). We requested and received the primary discharge diagnosis of AMI and asthma patients based on the international classification of the disease (ICD-9-CM code: 410 and 493) for both Delaware and non-Delaware resident patients over the age of 18. Other information requested was: age, sex, quarter of discharge, and state of residence. Patient anonymity and confidentiality was preserved since unique identifiable patient information was neither requested nor provided to the investigators. We included this in the primary analysis. Accordingly, the data was provided in an Excel spreadsheet format. From this data, we extracted the quarterly numbers pertaining to AMI and asthma based on the ICD-9 diagnosis codes. Moreover, we excluded data for 4th quarter of 2002 because the smoking ordinance took effect in November of that year. 


\subsection{Statistical Analysis}

The statistical analysis included both AMI and asthma rates for both Delaware and non-Delaware residents discharged from state hospitals in the database. The population of Delaware had undergone some change from 1999 to 2004 (census data estimated a 7.6\% increase from 2000 to 2005). We used population data from Delaware Vital Statistics Report from 2000 to 2004, and estimated the 1999 population [19]. From the 2004 report, the proportion of females in Delaware in 2000 was $51.4 \%$ and the projected proportion of females in 2010 was $51.5 \%$. Therefore, the effect of sex can be ignored. The vital reports do not have direct information regarding the mean age in the state. Thus, we looked over the proportion for ages 65 and older. This proportion slightly increased from $13.0 \%$ in 2000 to $13.8 \%$ in 2004 . Due to a relatively short time interval (24 quarters), we did not adjust for the proportion of elderly, which seems to be slightly conservative. The primary outcome variables examined were AMI and asthma quarterly counts. As a result, primary analyses for Delaware residents were based on the Poisson regression model with adjustment for population. However, the primary analyses for non-Delaware residents could be only based on the Poisson regression model without adjustment for population. Obviously, the non-Delaware data were from a much smaller 'population'. Therefore, when comparing results from Delaware and non-Delaware residents, we are not only interested in whether it is statistically significant but also pay attention to the magnitude of the relative risk (RR).

First, Poisson regression models were fitted for the number of AMI and asthma events by taking into consideration both the ordinance and seasonal effects. If the seasonal effect was not significant, a simpler Poisson regression model - with only the ordinance effect-was used. Accordingly, this was equivalent to comparing Poisson distributions before and after the ordinance. Resultantly, the risk ratio (RR) for the ordinance (before versus after) was reported together with a 95\% confidence interval. If seasonal effect was not included, quarterly rates before and after the smoking ordinance were estimated together with the standard error.

Analyses was performed separately for AMI and asthma cases for both Delaware and non-Delaware residents. Additionally, for AMI, the pre-ordinance and post-ordinance quarterly rates were subtracted to determine the average quarterly decrease. This number was then multiplied by the number of post-ordinance quarters $(n=8)$ to determine the two-year post-ordinance decrease in AMI.

Finally, we included a linear trend term in the Poisson regression models for our secondary analyses. We also used the data prior the ordinance to check for a temporal trend. These analyses are exploratory and have certain limitations. Since the population is growing in general, the Poisson regression without adjustment for the population for non- Delaware residents seems to be conservative with respect to the ordinance effect.

\section{Results}

\subsection{AMI}

After the amendment of the Delaware Clean Indoor Air Act at the end of 2002, a statistically significant reduction in the incidence of AMI for Delaware residents was observed ( $<<0.001)$ based on a Poisson regression model adjusted by season (with adjustment for the population). The RR for the 
post-ordinance vs. the pre-ordinance AMI was found to be 0.91 (95\% CI, 0.87 to 0.95). Seasonal effect was not found to be significant $(\mathrm{p}=0.154)$ for AMI and therefore, a Poisson regression model was fitted with only the ordinance effect, which gave similar results - RR for the post-ordinance vs. the pre-ordinance being 0.91 ( $\mathrm{p}<0.001,95 \% \mathrm{CI}, 0.88$ to 0.95 ) (Tables 1 and 2).

Table 1. Comparison of Delaware to Non-Delaware Resident Quarterly and Annual Incidence of Acute Myocardial Infarction.

\begin{tabular}{|c|c|c|c|c|c|c|c|c|c|c|}
\hline \multicolumn{6}{|c|}{ Delaware Residents } & \multicolumn{5}{|c|}{ Non-Delaware Residents } \\
\hline Year & $\begin{array}{c}\text { Quarter } \\
1 \\
\end{array}$ & $\begin{array}{c}\text { Quarter } \\
2 \\
\end{array}$ & $\begin{array}{c}\text { Quarter } \\
3 \\
\end{array}$ & $\begin{array}{c}\text { Quarter } \\
4 \\
\end{array}$ & $\begin{array}{c}\text { Annual } \\
\text { Total }\end{array}$ & $\begin{array}{c}\text { Quarter } \\
1 \\
\end{array}$ & $\begin{array}{c}\text { Quarter } \\
2 \\
\end{array}$ & $\begin{array}{c}\text { Quarter } \\
3 \\
\end{array}$ & $\begin{array}{c}\text { Quarter } \\
4\end{array}$ & $\begin{array}{c}\text { Annual } \\
\text { Total } \\
\end{array}$ \\
\hline 1999 & 435 & 430 & 415 & 453 & 1733 & 83 & 76 & 97 & 67 & 323 \\
\hline 2000 & 455 & 421 & 417 & 468 & 1761 & 66 & 82 & 84 & 72 & 304 \\
\hline 2001 & 479 & 495 & 506 & 465 & 1945 & 65 & 100 & 102 & 103 & 370 \\
\hline 2002 & 475 & 430 & 425 & $\begin{array}{l}\text { 438-not } \\
\text { included }\end{array}$ & 1768 & 97 & 102 & 104 & $\begin{array}{c}\text { 98-not } \\
\text { included }\end{array}$ & 401 \\
\hline 2003 & 463 & 439 & 440 & 473 & 1815 & 81 & 87 & 94 & 92 & 354 \\
\hline 2004 & 438 & 429 & 384 & 375 & 1626 & 81 & 94 & 83 & 67 & 325 \\
\hline
\end{tabular}

Table 2. Pre-ordinance vs. Post-Ordinance Quarterly Rates of AMI and Asthma for Delaware and Non-Delaware Residents.

\begin{tabular}{|c|c|c|c|}
\hline & $\begin{array}{l}\text { Pre-ordinance } \\
\text { Quarterly Rate }^{*}\end{array}$ & $\begin{array}{l}\text { Post-ordinance } \\
\text { Quarterly Rate* }\end{array}$ & $\begin{array}{c}\text { Pre-ordinance vs. Post-ordinance } \\
\text { Relative Risk (RR) }\end{array}$ \\
\hline \multicolumn{4}{|c|}{ Delaware Residents } \\
\hline AMI & 451 & 430 & $\begin{array}{c}0.95(P \text {-value } 0.022,95 \% \text { CI } 0.91-0.99)^{\dagger} \\
0.91(P \text {-value }<0.001,95 \% \text { CI } 0.87-0.95)^{\ddagger}\end{array}$ \\
\hline Asthma & 276 & 278 & $\begin{array}{c}0.99\left(P \text {-value } 0.770,95 \% \text { CI } 0.94 \text { to } 1.04^{\dagger}\right. \\
0.95(P \text {-value } 0.038,95 \% \text { CI } 0.90-0.99)^{\ddagger}\end{array}$ \\
\hline \multicolumn{4}{|c|}{ Non-Delaware Residents } \\
\hline AMI & 87 & 85 & $0.98(P \text {-value } 0.726,95 \% \text { CI } 0.90-1.08)^{\dagger}$ \\
\hline Asthma & 28 & 47 & $1.62(P \text {-value }<0.001,95 \% \text { CI } 1.41-1.86)^{\dagger}$ \\
\hline
\end{tabular}

${ }^{*}$ Not adjusted for population or seasonal effect; ${ }^{\dagger}$ Non-population adjusted analysis; ${ }^{\dagger}$ Population adjusted analysis

Before the smoking ordinance was enacted in Delaware, quarterly rates of AMI were $451(\mathrm{se}=21)$ and subsequently decreased to $430,(\mathrm{se}=21)$ demonstrating a $4.7 \%$ reduction. Taking into account the difference between pre-ordinance and post-ordinance quarterly rates of AMI, we observed a noticeable decline in AMI rates after the enforcement of the statewide comprehensive ordinance. Consequently, this resulted in approximately 169 fewer AMI cases over the 8 quarter post-ordinance period.

In comparison, similar calculations performed for non-Delaware residents included in the Delaware Discharge Database showed no ordinance effect $(\mathrm{p}=0.726)$ based on population adjusted model with season effect. Consequently, non-Delaware residents discharged from Delaware hospitals had similar pre-ordinance and post-ordinance AMI risk (RR 0.98, 95\% CI, 0.90 to 1.08, $P=0.726$ ) (Tables 1 and 2).

To examine possible temporal trend, we first fitted a Poisson regression model including season and a linear trend term (with adjustment for population) based on the prior ordinance Delaware resident data. The linear trend term turned out to be insignificant $(\mathrm{p}=0.924)$. Again, a model including 
ordinance, season and linear trend using pre and post ordinance data showed that the linear trend is not significant $(\mathrm{p}=0.557)$.

Therefore, for Delaware residents there was a statistically significant decrease in the number of AMI discharges post-ordinance. However, for non-Delaware residents ordinance did not show a significant impact on AMI.

\subsection{Asthma}

When examining asthma rates in Delaware residents (adjusted for population) the results show a significant ordinance effect $(\mathrm{p}=0.046)$ together with a strong seasonal effect $(\mathrm{p}<0.001)$. The RR for ordinance (post $v s$. pre) was 0.95 with a $95 \%$ CI, 0.90 to 0.99 , which represents a significant reduction in quarterly asthma discharges from pre-ordinance to post-ordinance (Table 2 and 3 ).

In comparison, for asthma in non-Delaware residents, both the seasonal ( $(\mathrm{p}<0.001)$ and ordinance effect ( $\mathrm{p}<0.001)$ were significant. The RR (post $v$ s. pre) for ordinance is estimated at $1.62(95 \% \mathrm{CI}$, 1.41 to 1.86), indicating a significant increase in the rates of asthma from pre-ordinance to post-ordinance (Tables 2 and 3).

Table 3. Comparison of Delaware to Non-Delaware Resident Quarterly and Annual Incidence of Asthma.

\begin{tabular}{|c|c|c|c|c|c|c|c|c|c|c|}
\hline \multicolumn{5}{|c|}{ Delaware Residents } & \multicolumn{5}{c|}{ Non-Delaware Residents } \\
\hline Year & $\begin{array}{c}\text { Quarter } \\
1\end{array}$ & $\begin{array}{c}\text { Quarter } \\
2\end{array}$ & $\begin{array}{c}\text { Quarter } \\
3\end{array}$ & $\begin{array}{c}\text { Quarter } \\
4\end{array}$ & $\begin{array}{c}\text { Annual } \\
\text { Total }\end{array}$ & $\begin{array}{c}\text { Quarter } \\
1\end{array}$ & $\begin{array}{c}\text { Quarter } \\
2\end{array}$ & $\begin{array}{c}\text { Quarter } \\
3\end{array}$ & $\begin{array}{c}\text { Quarter } \\
4\end{array}$ & $\begin{array}{c}\text { Annual } \\
\text { Total }\end{array}$ \\
\hline 1999 & 289 & 278 & 289 & 344 & 1200 & 19 & 19 & 28 & 34 & 100 \\
\hline 2000 & 271 & 242 & 202 & 348 & 1063 & 21 & 23 & 24 & 45 & 113 \\
\hline 2001 & 297 & 296 & 218 & 334 & 1145 & 32 & 27 & 16 & 46 & 121 \\
\hline 2002 & 298 & 206 & 230 & $\begin{array}{c}305-n o t \\
\text { included }\end{array}$ & 1039 & 31 & 31 & 30 & $35-$ not & 127 \\
\hline 2003 & 244 & 291 & 266 & 375 & 1176 & 40 & 32 & 45 & 73 & 190 \\
\hline 2004 & 253 & 240 & 223 & 336 & 1052 & 59 & 41 & 37 & 50 & 187 \\
\hline
\end{tabular}

Similar to AMI, a Poisson regression model including season and a linear trend term (with adjustment for population) based on the prior ordinance Delaware resident data was fitted. The linear trend term is significant $(\mathrm{p}<0.001)$ and so is the season $(\mathrm{p}<0.001)$. The RR (a year vs. previous year) was 0.95 (95\% CI 0.93 to 0.98); indicating a decreasing asthma rate in time. In a model including ordinance, season and linear trend (using pre and post ordinance data), ordinance ( $p=0.025)$, season $(\mathrm{p}<0.001)$ and linear trend $(\mathrm{p}<0.001)$ are all significant. The RR for linear trend (year) is $0.95(95 \%$ CI 0.92 to 0.97 ). However, ordinance showed a revise effect (post $v s$. pre RR $=1.12,95 \%$ CI 1.01 to 1.24). Similar analyses were performed for non-Delaware resident data. For pre ordinance data, the linear trend is not significant $(\mathrm{p}=0.064)$. For both pre and post ordinance data, the season $(\mathrm{p}<0.001)$ and linear trend (year) $(\mathrm{p}=0.036)$ are significant but the ordinance is not significant $(\mathrm{RR}=1.23$, $\mathrm{p}=0.161)$. However, the temporal trend for asthma was increasing in time (RR for year $=1.09,95 \%$ CI 1.01 to 1.19 ). 
Combining the results from the analyses with and without adjustment of temporal trend, the RR for ordinance for Delaware residents ranged from 0.95 (without temporal trend) to 1.12 (with temporal trend), while the one for non-Delaware residents ranged from 1.23 (with temporal trend) to 1.62 (without temporal trend). It is also noted that the temporal trends obtained for Delaware and nonDelaware data are in opposite directions (decreasing for Delaware and increasing for non-Delaware). As a result, the Delaware residents are likely to be protected for asthma when compared with nonDelaware residents, during the post-ordinance period.

\section{Discussion}

Currently, eight states have comprehensive statewide non-smoking ordinances in the US [9]. Additionally, over half of the entire US population is covered by at least a partial non-smoking ordinance [10]. Accordingly, previous studies have addressed some of the health benefits of smoking bans, which found significant decreases in the incidence of AMI when comprehensive non-smoking ordinances were enacted in the absence of prior partial smoking bans (Helena, Pueblo, and Piedmont) [5-7]. However, these studies did not address the issues of statewide non-smoking ordinances or partial to comprehensive smoking bans. Consequently, the present study addressed both issues and found statistically significant decreases in both the AMI and asthma discharge rates for a statewide non-smoking ordinance that was amended from a partial to a comprehensive ban on smoking. In addition, the asthma results of the present study are shown to have an added health benefit of non-smoking ordinances that had not been previously analyzed.

\subsection{AMI}

With the amendment of the Delaware Clean Indoor Air Act in 2002, the relative risk of having an AMI after adjusting for population growth was $9 \%$ less when compared to the pre-ordinance risk. It is estimated that as a direct consequence of the ordinance, it can be calculated that there have been approximately 340 fewer AMI discharges and potentially 27 lives saved (assuming 7.8\% of AMI admissions end in death [20]) among Delaware residents during the 2003-2004 post-ordinance period.

In comparison to previous studies, the 2002 Delaware smoking ordinance effect on the incidence of AMI was significantly smaller (9\% in Delaware after population adjustment, versus $11 \%$ in Piedmont, $27 \%$ in Pueblo, $47 \%$ in Helena and 17\% in Toronto, respectively) [5-8]. Nevertheless, Delaware may have been experiencing health benefits like decreased rates of AMI and asthma since 1994 due to its partial smoking ban, and in 2002, when the ordinance became comprehensive, the health benefits for the state would be only modestly augmented.

The smaller effect on the size and rate of AMI may also be explained in part by a change in its clinical definition, which took place during our study period. In 2000, the European Society of Cardiology/American College of Cardiology changed the diagnostic criteria for the definition of AMI to include the use of troponins [21,22]. Consequently, a 2006 study applying the new criteria found that the inclusion of troponins in the definition resulted in a large increase in the annual number of patients diagnosed with AMI [23]. Although this new definition was released in 2000, its gradual increased use over our study period may have blunted the observed effect of the comprehensive smoking ordinance. 


\subsection{Asthma}

There has been little published analysis on the health benefits of non-smoking ordinances on their effects on asthma. Most notably, a recent Canadian Medical Association Journal (CMAJ) article agreed with our study [8]; we found that there was a statistically significant decrease in the incidence of asthma discharges among Delaware residents after the introduction of a statewide non-smoking ordinance. As expected, this effect did not carry over into non-Delaware residents and in fact, our research found the opposite effect. We found that non-Delaware residents were shown to have a large increase in the incidence of asthma discharges during the post-ordinance as compared to the preordinance period. Although there is no clear explanation for this increase, it could be due in part to increases of surrounding populations or other health related factors.

\subsection{Limitations}

Our study did not examine the period before the partial non-smoking ban (i.e., prior to 1994) because such information was not readily available from the Delaware Hospital Discharge Database. Similarly, there was lack of available data for the surrounding states on smoke-free polices and therefore, we were unable to compare our data across neighboring states. Moreover, this study was not able to track the large number of patients with asthma - who may have been treated in the emergency department and then released - that may have been protected from exacerbations by the smoke-free policy. Additionally, there is a limitation for the temporal trend used in this study. Even if national data is available, it may not represent the temporal trend in the State of Delaware as the actual trends may be non-linear. Accordingly, the ordinance effect by may be offset by the linear trend term in the model. We must emphasize that our observational data cannot prove causality, it can only provide statistical association between the variables we analyzed in the present study. Finally, individuals under the age of 35 will likely have a different mechanism for AMI - such as a congenital defect - meaning when these cases are combined with older adults, it may create a heterogeneous group that may respond to SHS differently. It is recommended that future studies can perhaps address and compare all three periods in the life of the Delaware Clean Indoor Air Act or similar acts: with the pre non-smoking ban, partial non-smoking ban, and comprehensive non-smoking ban being analyzed.

\section{Conclusions}

The results of our study can be added to the growing list of scientific findings from other studies which demonstrate the real and practical cardiovascular health benefits gained by initiating comprehensive anti-smoking ordinances. It showed that there is very little question regarding the added health benefits that can be gained by strengthening existing smoking bans. Moreover, we were able to demonstrate an additional advantage offered by comprehensive non-smoking ordinances by effectively and meaningfully displaying a statistical association in the reduction of asthma discharge rates. This unique finding, added to the cardiovascular health benefits already recognized and widely reported in the scientific literature, may encourage more communities and regions to join those who currently have comprehensive non-smoking ordinances and potentially experience additional health benefits as shown in this paper. 


\section{Acknowledgements}

The authors would like to thank Karen Dawson for administrative assistance and Alexander Steffen for editing and support.

\section{References and Notes}

1. Mokdad, A.H.; Marks, J.S.; Stroup, D.F.; Gerberding, J.L. Actual causes of death in the United States, 2000. J. Am. Med. Assoc. 2004, 291, 1238-1245.

2. Teo, K.K.; Ounpuu, S.; Hawken, S.; Pandey, M.R.; Valentin, V.; Hunt, D.; Diaz, R; Rashed, W.; Freeman, R.; Jiang, L.; Zhang, X.; Yusuf, S. Tobacco use and the risk of myocardial infarction in 52 countries in the INTERHEART study: A case-control study. Lancet 2006, 368, 647-58.

3. Thompson, N.C.; Chaudhuri, R.; Livingston, E. Asthma and cigarette smoking. Eur. Respir. J. 2004, 24, 822-833.

4. Eisner, M.D.; Klein, J.; Hammond, S.K.; Koren, G.; Lactao, G.; Iribarren, C. Directly measured second hand smoke exposure and asthma health outcomes. Thorax 2005, 60, 814-821.

5. Sargent, R.P.; Shepard, R.M.; Glantz, S.A. Reduced incidence of admissions for acute myocardial infarction associated with public smoking ban: Before and after study. Brit Med J. 2004, 238, 977-983.

6. Bartecchi, C.; Alsever, R.N.; Nevin-Woods, C.; Thomas, W.M.; Estacio R.O.; Bartelson, B.B.; Krantz, M.J. Reduction in the incidence of acute myocardial infarction associated with a citywide smoking ordinance. Circulation 2006, 114, 1490-1496.

7. Barone-Adesi, F.; Vizzini, L.; Merletti, F.; Richiardi, L. Short-term effects of Italian smoking regulation on rates of hospital admission for acute myocardial infarction. Eur. Heart J. 2006, 27, 2468-2472.

8. Naiman, A.; Glazier, R.; Moineddin, R. Association of anti-smoking legislation for cardiovascular and respiratory conditions. Can. Med. Assn. J. 2010, 182,761-767.

9. Rayens, M.K.; Burkhart, P.V.; Patricia, V.; Zhang, M.; Lee, S.; Moser, D.; Mannino, D; Hahn, E. Reduction in asthma-related emergency department visits after implementation of a smoke-free law. Allergy Clin. Immunol. 2008, 122, 537-541.

10. American Nonsmokers' Rights Foundation. States, Commonwealths, and Municipalities with 100\% Smokefree Laws in Workplaces, Restaurants or Bars. Available online: http://www.nosmoke.org/pdf/100ordlist.pdf (accessed on 13 April 2007).

11. American Nonsmokers' Rights Foundation. Summary of $100 \%$ Smokefree State Laws and Population Protected by $100 \%$ U.S. Smokefree Laws. Available online: http://www.nosmoke.org/pdf/SummaryUSPopList.pdf (accessed on 13 April 2007).

12. U.S. Census Bureau. State and County Quick Facts: Delaware. Available online: http://quickfacts.census.gov/qfd/ states/10000.html (accessed on 21 March 2007).

13. U.S. Census Bureau. Delaware: 2000. August 2000. Available online: http://www.census.gov/ prod/2002pubs/ c2kprof00-de.pdf (accessed on 21 March 2007).

14. U.S. Census Bureau. American Factfinder. Available online: http://factfinder.census.gov/ servlet/DatasetMainPageServlet?program=DEC\&_submenuId=\&_lang=en\&_ts (accessed on 21 March 2007). 
15. Behavioral Risk Factor Surveillance System Survey Data; Centers for Disease Control and Prevention (CDC): Atlanta, GA, USA, 2004.

16. Cigarette Smoking among Adults - United States, 1999; Morbidity and Mortality Weekly Report (MMWR). CDC: Atlanta, GA, USA, 2001.

17. Clean Indoor Air Act 2002; Delaware Code Title 16; Government of Delaware: Wilmington, DE, USA, 2002.

18. Smokefree Ohio Compliance and Enforcement of Clean Indoor Air Laws. Smokefree Ohio: Dublin, OH, USA, August 2006. Available online: http://www.smokefreeohio.org/oh/ (accessed on 6 February 2007).

19. Gladders, B.; Ratledge, E.; Ruggiero, T. Delaware Hospital Discharge Summery Report; Delaware Health Statistics Center: New Castle, DE, USA, 2006; pp. 1-71.

20. Merrill, C.T.; Elixhauser, A. Hospitalization in the United States 2002. Available online: http://www.ahrq.gov/data/hcup/factbk6/ (accessed on 17 April, 2007).

21. Alpert, J.S.; Thygesen, K.; Antman, E.; Bassand, J.P. Myocardial infarction redefined: A consensus document of The Joint European Society of Cardiology/American College of Cardiology Committee for the redefinition of myocardial infarction. J. Am. Coll. Cardiol. 2000, 36, 959-969.

22. Apple F.S.; Wu, A. Myocardial infarction redefined: Role of cardiac troponin testing. Clin. Chem. 2001, 47, 377-379.

23. Veronique, R.L.; Killian, J.M.; Weston, S.A.; Jaffe, A.S.; Kors, J.; Santrach, P.J.; Tunstall-Pedoe, H.; Jacobsen, S.J. Redefinition of myocardial infarction: prospective evaluation in the community. Circulation 2006, 114, 790-797.

(C) 2010 by the authors; licensee MDPI, Basel, Switzerland. This article is an open access article distributed under the terms and conditions of the Creative Commons Attribution license (http://creativecommons.org/licenses/by/3.0/). 